\title{
Effects of annealing treatment on tribological behavior of tungsten-doped diamond-like carbon film under lubrication (Part 2): Tribological behavior under MoDTC lubrication
}

\author{
Shaojun ZHANG ${ }^{1}$, Lina ZHU ${ }^{1,2, *}$, Yanyan WANG ${ }^{1}$, Jiajie KANG ${ }^{1,2}$, Haidou WANG ${ }^{3,4}$, Guozheng MA ${ }^{4}$, Haipeng \\ HUANG ${ }^{5}$, Guang'an ZHANG ${ }^{6}$, Wen YUE ${ }^{1,2, *}$ \\ ${ }^{I}$ School of Engineering and Technology, China University of Geosciences (Beijing), Beijing 100083, China \\ ${ }^{2}$ Zhengzhou Research Institute, China University of Geosciences (Beijing), Zhengzhou 451283, China \\ ${ }^{3}$ National Engineering Research Center for Remanufacturing, Beijing 100072, China \\ ${ }^{4}$ National Key Lab for Remanufacturing, Academy of Armored Forces Engineering, Beijing 100072, China \\ ${ }^{5}$ Beijing Research Institute, Sinopec Lubricant Co., Ltd., Beijing 100085, China \\ ${ }^{6}$ State Key Laboratory of Solid Lubrication, Lanzhou Institute of Chemical Physics, Chinese Academy of Sciences, Lanzhou 730000, China \\ Received: 16 July 2020; Revised: 16 December 2020; Accepted: 30 March 2021 \\ (C) The author(s) 2021.
}

\begin{abstract}
Molybdenum dialkyldithiocarbamate (MoDTC) is widely used as a friction modifier in engine lubricating oil. Under MoDTC lubrication, the friction and wear behaviors of tungsten-doped diamond-like carbon (W-DLC) films annealed at $100-400{ }^{\circ} \mathrm{C}$ were discussed and evaluated using scanning electron microscopy (SEM), atomic force microscopy (AFM), and Raman spectroscopy. Under (polymerized alpha olefin) PAO + MoDTC lubrication, the coefficient of friction of all samples decreased, but the wear rates of the W-DLC films annealed at $300{ }^{\circ} \mathrm{C}$ increased significantly. By interacting with zinc dialkyldithiophosphate (ZDDP), the wear rates of W-DLC films annealed at different temperatures declined significantly owing to the formation of dense phosphate tribofilms on the worn surfaces.
\end{abstract}

Keywords: diamond-like carbon (DLC); annealing; friction and wear behaviors; molybdenum dialkyldithiocarbamate (MoDTC); zinc dialkyldithiophosphate (ZDDP)

\section{Introduction}

The efficiency and life of the engine affects its energy saving and economic performance. Low-viscosity lubricants, friction modifiers, and lubricated coatings can effectively reduce the coefficient of friction (COF) and improve the engine fuel economy. Diamond-like carbon (DLC) films are also widely used in engine systems owing to their high hardness, good lubrication performance, and chemical inertness [1-4]. DLC films are metastable amorphous structures composed of $\mathrm{sp}^{2}$ and $\mathrm{sp}^{3}$ carbon bonds $\left(\mathrm{sp}^{2}-\mathrm{C}\right.$ and $\left.\mathrm{sp}^{3}-\mathrm{C}\right)$. However, the conversion from $\mathrm{sp}^{3}-\mathrm{C}$ into $\mathrm{sp}^{2}-\mathrm{C}$ occurs at high temperatures, resulting in a change in the structure and properties of DLC films [5-8]. The working temperature of the engine is $120-150{ }^{\circ} \mathrm{C}[9,10]$. Moreover, the flash temperature during the friction process may reach $200{ }^{\circ} \mathrm{C}$, which is an important factor for increasing the temperature of the working surface $[11,12]$.

Tungsten achieves excellent frictional properties at high temperatures in DLC films. In air, tungstendoped DLC films have stable tribological properties at high temperatures $\left(400-500{ }^{\circ} \mathrm{C}\right)$, owing to the oxidation

* Corresponding authors: Lina ZHU, E-mail: zhulina@cugb.edu.cn; Wen YUE, E-mail: cugbyw@163.com 
of $\mathrm{W}$ into $\mathrm{WO}_{3}$ (tungsten content of approximately $20 \mathrm{wt} \%$ ) [13-15], leading to the application of W-DLC films in automobile engines, such as on the surfaces of the valves and cams [16, 17]. In addition, lubricants are conducive to the removal of abrasive particles, and additives can further reduce friction and wear [18, 19]. Therefore, the tribological properties of W-DLC films annealed at different temperatures under oil lubrication have been discussed.

MoDTC is commonly used as a friction modifier, which can be decomposed into tribofilms on counter surfaces. The tribofilms are mainly composed of $\mathrm{N}$, $\mathrm{C}$, and $\mathrm{O}$, with nanoscale embedded $\mathrm{MoS}_{2}$, and thus MoDTC exhibits friction reduction properties during the friction process [20-22]. As a type of anti-friction film, DLC films are expected to further reduce the frictional loss and interact with MoDTC. However, previous studies have shown that MoDTC aggravates the wear of DLC films [23-29]. Some studies have considered that $\mathrm{MoO}_{3}$ particles decomposed from MoDTC become abrasive during the friction process, which worsens the wear of DLC films [23-26]. In recent years, current studies have focused on the reasons for the increased wear of DLC films lubricated with MoDTC, and it was found that $\mathrm{Mo}_{2} \mathrm{C}$ particles, produced by tribochemical reactions between DLC films and MoDTC, are the main contributor [27-29].

MoDTC reacting with other additives has been universally investigated, particularly the interaction between MoDTC and ZDDP (the most widely used extreme agent) [30-37]. It was found that a carbonrich amorphous phosphate structure was formed on the worn surfaces, and $\mathrm{MoS}_{2}$ was embedded in the gaps of pad-like phosphate structures under MoDTC and ZDDP lubrication conditions [31, 32]. Moreover, by interacting with DLC films, ZDDP can suppress the wear caused by MoDTC [32-34]. The formation of tribofilms depends on the worn surfaces, based on the physical adsorption and chemical reaction of additives on the worn surfaces. Therefore, changes in the chemical composition of DLC films greatly affect their mechanical properties and tribological behavior by interacting with additives, altering the efficiency and service life of the engine [25, 26, 38-40].

In Section 2 of this study, the effects of annealing temperature on the morphology, chemical structure, and mechanical properties of W-DLC films were investigated, along with the friction and wear behavior under PAO lubrication. With an increase in the annealing temperature, the thickness of the W-DLC film decreases because of the graphitization. Moreover, oxygen was obtained on the unworn surfaces of W-DLC films annealed at $400{ }^{\circ} \mathrm{C}$. When the annealing temperature reached $500{ }^{\circ} \mathrm{C}$, the films were destroyed. The hardness and elastic modulus of the W-DLC films decreased with an increase in the annealing temperature. Under PAO lubrication, a lower COF was observed for the films annealed at 200 and $300{ }^{\circ} \mathrm{C}$ compared with those annealed at other temperatures. This was attributed to the fact that the proper increase in the $\mathrm{sp}^{2}-\mathrm{C}$ bond has a positive effect on the removal of the wear particles. Based on Section 2, the effects of annealing temperature on the friction and wear behavior of W-DLC films with MoDTC and MoDTC + ZDDP additives are discussed in Section 3.

\section{Experimental}

\subsection{Materials and lubricants}

W-DLC films were deposited on an AISI 316 L stainless steel substrate through magnetron sputtering (W content of 4.5 at $\%$ ) with a thickness of $2.2 \mu \mathrm{m}$. Furthermore, the W-DLC films were annealed at 100, $150,200,300,400$, and $500{ }^{\circ} \mathrm{C}$ in the atmosphere, and the unannealed films were labeled as $25{ }^{\circ} \mathrm{C}$ W-DLC films.

The base oil used in the tribotests was synthetic polyalpha olefin (PAO-4), with a viscosity of $16.68 \mathrm{~mm}^{2} / \mathrm{s}$ at $40{ }^{\circ} \mathrm{C}$ and $3.84 \mathrm{~mm}^{2} / \mathrm{s}$ at $100{ }^{\circ} \mathrm{C}$, respectively. The concentrations of MoDTC (Mo: $10.0 \mathrm{wt} \%$ and S: $11.0 \mathrm{wt} \%$ ) and ZDDP (Zn: $10.0 \mathrm{wt} \%$, P: $8.0 \mathrm{wt} \%$, and S: $16.0 \mathrm{wt} \%$ ) were both $1 \mathrm{wt} \%$. The lubricating conditions are listed in Table 1. The wear radius of the steel balls in Eq. (1) was measured using an optical microscope. The wear volumes $V\left(\mathrm{~m}^{3}\right)$ of the steel balls were calculated

Table 1 Oils and additive contents.

\begin{tabular}{ccc}
\hline \multirow{2}{*}{ Oil } & \multicolumn{2}{c}{ Additive type } \\
\cline { 2 - 3 } & MoDTC & ZDDP \\
\hline PAO & - & - \\
PAO + MoDTC & $1 \mathrm{wt} \%$ & - \\
PAO + MoDTC + ZDDP & $1 \mathrm{wt} \%$ & $1 \mathrm{wt} \%$ \\
\hline
\end{tabular}


using Eq. (1) [25]:

$$
V=\frac{1}{6} \pi h\left(3 r^{2}+h^{2}\right)
$$

where $h=R-\sqrt{R^{2}-r^{2}}, R$ is the radius of a steel ball $(0.003 \mathrm{~m})$, and $r$ is the radius of the wear scar $(\mathrm{m})$ on the ball.

The Archard wear equation [25] was used to calculate the wear rates of the W-DLC films and steel balls:

$$
k_{\mathrm{w}}=\frac{V}{F \cdot S}
$$

where $k_{\mathrm{w}}$ is the wear rate per unit load and per unit distance $\left(\mathrm{m}^{3} /(\mathrm{N} \cdot \mathrm{m})\right), F$ is the normal load $(\mathrm{N})$, and $S$ is the sliding distance $(\mathrm{m})$.

The minimum thickness of the oil films was calculated using the Dawson equation [25]:

$$
\begin{gathered}
h_{\min }=3.63 R\left(U^{*}\right)^{0.68} \cdot\left(w^{*}\right)^{-0.073} \cdot\left(G^{*}\right)^{0.49} \cdot\left(1-\mathrm{e}^{-0.68 k}\right) \\
\lambda=h_{\min } /\left(R_{\mathrm{a} \text {-ball }}^{2}+R_{\mathrm{a} \text {-disc }}^{2}\right)^{0.5}
\end{gathered}
$$

where $U^{*}=\eta_{0} U / E^{*}, G^{*}=\alpha / E^{*}, w^{*}=P / E^{*} R^{2}, \eta_{0}$ is the dynamic viscosity $\left(3.26 \times 10^{-3} \mathrm{~Pa} \cdot \mathrm{s}\right.$ at $\left.100{ }^{\circ} \mathrm{C}\right), \alpha$ is the viscosity-pressure coefficient $\left(3.5 \times 10^{-8} \mathrm{~Pa}^{-1}\right.$ at $\left.100{ }^{\circ} \mathrm{C}\right), R$ is the radius of the ball $(3 \mathrm{~mm}), U$ is the linear speed $(0.02 \mathrm{~m} / \mathrm{s}), P$ is the normal load $(10 \mathrm{~N}), E^{*}$ is the effective modulus of elasticity (98.3-101.01 GPa) calculated according to the elastic modulus of the ball (213 GPa) and annealed W-DLC films (166.8$176.5 \mathrm{GPa})$, and $k$ is an elliptical parameter, which is equal to 1.03 for point contact mode. $R_{\text {a-ball }}(2 \mathrm{~nm})$ and $R_{\mathrm{a} \text {-disc }}(1.45-3.20 \mathrm{~nm})$ are the roughnesses of the ball and the annealed W-DLC films, respectively. The values of $\lambda$ were $0.085-0.091(\lambda<1)$, which indicates that all tribotests were operated under boundary lubrication.

\subsection{Experimental parameters}

The friction and wear behavior of W-DLC films $(20 \mathrm{~mm} \times$ $20 \mathrm{~mm} \times 3 \mathrm{~mm}$ ) were tested using a ball-on-disc tribometer, of which the counter-bodies were AISI 52100 steel balls. All tribotests were carried out in reciprocating mode with a load of $10 \mathrm{~N}$ at a temperature of $100{ }^{\circ} \mathrm{C}$, and the contact stresses were approximately $0.9 \mathrm{GPa}$. The maximum sliding speed was $0.02 \mathrm{~m} / \mathrm{s}$.
The length of the wear tracks on the surfaces of the W-DLC films was $2 \mathrm{~mm}$. Furthermore, the total sliding distance was $48 \mathrm{~m}$ for 12,000 cycles.

The hardness and elastic modulus of the W-DLC films annealed at different temperatures were measured using a nanoindenter with a Berkovich diamond tip (Nanoindenter G2000, MTS, USA). The cross-sectional morphologies of the wear tracks were characterized using a 3D surface profilometer (AEP, NanoMap-D, USA). The surface and cross-sectional morphologies of the wear tracks on the W-DLC films were investigated by an scanning electron microscope (SEM, MERLIN Compact, Carl Zeiss, USA), and the elemental compositions of the wear scars on the counter bodies were determined through the energy-dispersive $\mathrm{X}$-ray spectroscope (EDS, equipped on SEM, Bruker XFlash 630, USA). Topographic images of the wear tracks on the W-DLC films were analyzed by the atomic force microscope (AFM, MFP-30, Asylum Research, USA). The chemical compositions of the unworn surfaces and wear tracks of W-DLC films were characterized by the Raman spectroscope (LabBram HR Evolution, HORIBA, Japan) scanning from 200 to $2,000 \mathrm{~cm}^{-1}$ for $60 \mathrm{~s}$ with a 532-nm wavelength laser source.

\section{Results}

\subsection{Characterization of W-DLC films}

The surface morphologies, chemical compositions, and mechanical and tribological properties with PAO lubrication of the W-DLC films annealed at different temperatures are discussed in Section 2. The thicknesses of the W-DLC films annealed at various temperatures decreased. W-DLC films graphitized with rising temperatures on the surfaces characterized by Raman spectra and further oxidized at $400{ }^{\circ} \mathrm{C}$. Remarkably, the $\mathrm{W}$-DLC films annealed at $500{ }^{\circ} \mathrm{C}$ were destroyed and failed. A smaller roughness of the films annealed at $400{ }^{\circ} \mathrm{C}$ occurred because of the oxidation of the W-DLC films. With the increase in annealing temperature, the roughness of the W-DLC films increased and the hardness of the W-DLC films decreased. Meanwhile, the elastic modulus of the samples was almost the same, except for a large decrease at $500{ }^{\circ} \mathrm{C}$. The decrease in $H / E$ and $H^{3} / E^{2}$ ratios ( $H$ and $E$ are the 
hardness and elastic modulus of annealed W-DLC films, respectively) reflected the deterioration of the plastic resistance and toughness of the W-DLC films. Under PAO lubrication, the W-DLC films annealed at $300{ }^{\circ} \mathrm{C}$ exhibited the lowest COF and wear rate among the annealing temperatures. The characteristics of the W-DLC films annealed at different temperatures are listed in Table 2.

\subsection{Friction and wear behavior}

Under different lubrication conditions, the COF as a function of the sliding cycles of the annealed W-DLC films is shown in Figs. 1(a) and 1(b). Figure 1(c) shows the COFs during the last 3,000 cycles under various lubrication conditions, and COFs under PAO lubrication are introduced in Section 2. The friction and wear behavior of W-DLC films annealed at $500{ }^{\circ} \mathrm{C}$ are not discussed because of the destruction of the films.

Under PAO + MoDTC lubrication, it can be pointed out that the $\mathrm{COF}$ is sensitive to annealing temperatures, as shown in Fig. 1(a). The COFs of the samples annealed at all temperatures were smooth with an increase in the sliding cycles. COFs with a variety of temperatures were lower than those of the base oil, indicating that MoDTC played a role in friction modification during the friction process. Furthermore, the $\mathrm{COF}$ of the sample annealed at $300{ }^{\circ} \mathrm{C}$ decreased furthest (29\%) compared with the unannealed W-DLC films, at approximately 0.08 , whereas those of samples annealed at $100-200{ }^{\circ} \mathrm{C}$ showed little difference.

Figure 1(b) shows the COF of the samples annealed at $25-400^{\circ} \mathrm{C}$ under PAO + MoDTC + ZDDP lubrication. The friction curves of the W-DLC films annealed at all temperatures were stable and almost the same, i.e., approximately 0.09 .

Under PAO + MoDTC and PAO + MoDTC + ZDDP lubrication, Figs. 2 and 3 show the cross-sectional morphologies and wear rates of W-DLC films annealed at different temperatures, respectively. It was observed that abrasive wear occurred on these W-DLC films under both lubrication conditions. Abrasive wear is a typical characteristic of DLC films lubricated with MoDTC [8]. It was noted that the depths of the wear tracks of W-DLC films annealed at changing temperatures lubricated with $\mathrm{PAO}+\mathrm{MoDTC}$ were smaller than those lubricated with PAO + MoDTC + ZDDP,

Table 2 Characteristics of W-DLC films annealed at different temperatures.

\begin{tabular}{cccccccc}
\hline Annealing temperature $\left({ }^{\circ} \mathrm{C}\right)$ & 25 & 100 & 150 & 200 & 300 & 400 & 500 \\
\hline Film thickness $(\mu \mathrm{m})$ & 2.20 & 2.18 & 2.08 & 1.92 & 1.80 & 1.75 \\
Roughness $(\mathrm{nm})$ & $1.45 \pm 0.09$ & $1.67 \pm 0.08$ & $1.66 \pm 0.16$ & $1.88 \pm 0.11$ & $2.29 \pm 0.18$ & $1.51 \pm 0.05$ & $3.20 \pm 0.40$ \\
$I_{\mathrm{D}} / I_{\mathrm{G}}$ of Raman spectra & 1.65 & 1.86 & 1.61 & 1.90 & 2.33 & 2.10 & 1.01 \\
$\quad$ G peak position of & $1,557.82$ & $1,557.15$ & $1,560.11$ & $1,569.25$ & $1,571.18$ & $1,581.14$ & $1,581.17$ \\
Raman spectra $\left(\mathrm{cm}^{-1}\right)$ & $15.2 \pm 1.5$ & $14.0 \pm 0.9$ & $13.9 \pm 0.8$ & $13.6 \pm 2.2$ & $11.8 \pm 1.5$ & $9.5 \pm 0.7$ & $0.8 \pm 0.1$ \\
Hardness $(\mathrm{GPa})$ & $176.5 \pm 5.6$ & $170.2 \pm 8.1$ & $169.0 \pm 6.2$ & $173.7 \pm 14.1$ & $169.2 \pm 15.6$ & $166.8 \pm 8.3$ & $65.1 \pm 4.7$ \\
Elastic modulus $(\mathrm{GPa})$ & & &
\end{tabular}

$I_{\mathrm{D}} / I_{\mathrm{G}}$ : the relative intensity ratio of the $\mathrm{D}$ and $\mathrm{G}$ peaks.
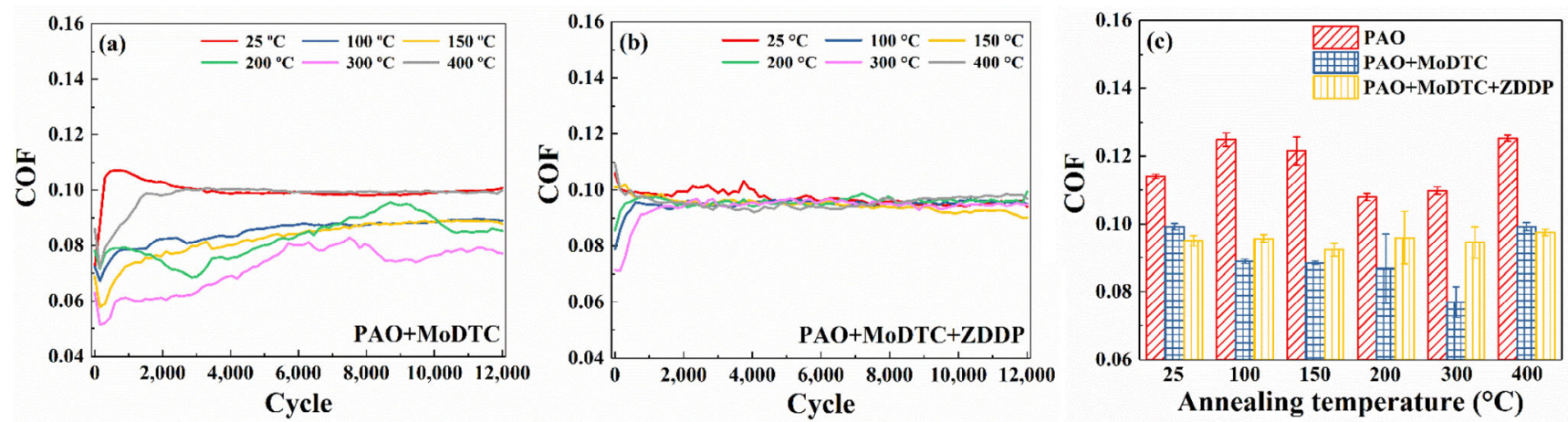

Fig. $1 \mathrm{COF}$ as a function of sliding cycles at annealing temperatures within the range of $25-400{ }^{\circ} \mathrm{C}$ lubricated with (a) PAO $+\mathrm{MoDTC}$ and (b) PAO + MoDTC + ZDDP, and (c) steady-state COFs for the last 3,000 cycles at the annealing temperature with different additives. 

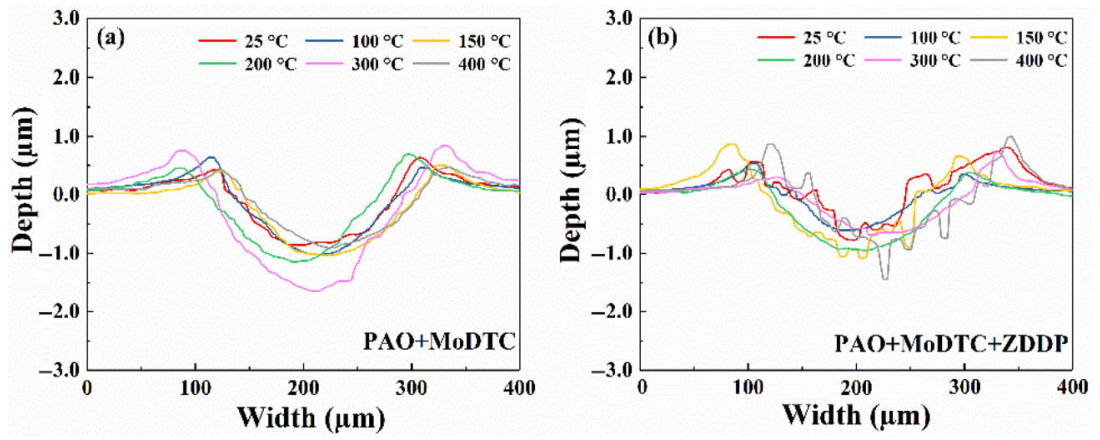

Fig. 2 Cross-sectional morphologies of wear tracks of W-DLC films lubricated with (a) PAO + MoDTC and (b) PAO + MoDTC + ZDDP.
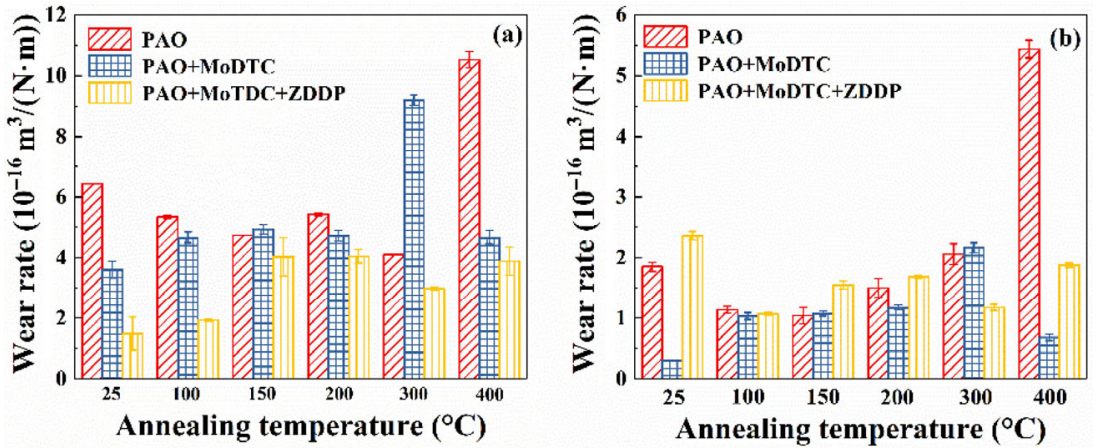

Fig. 3 Variation in wear rates with annealing temperature under different lubrications: (a) W-DLC films and (b) steel balls.

which proves that the addition of ZDDP has a positive effect on reducing the wear. Compared with the PAO + MoDTC lubrication, more furrows appeared on the wear tracks under PAO + MoDTC + ZDDP lubrication. Furthermore, the widths of the W-DLC films annealed at $150-300{ }^{\circ} \mathrm{C}$ were larger than those annealed at other temperatures under PAO + MoDTC lubrication.

Under PAO + MoDTC lubrication, the wear rates of the W-DLC films are shown in Fig. 3(a). The wear rate of the unannealed W-DLC film was $3.6 \times 10^{-16} \mathrm{~m}^{3} /(\mathrm{N} \cdot \mathrm{m})$, and that of the annealed films increased. It should be noted that W-DLC films annealed at $300{ }^{\circ} \mathrm{C}$ exhibited the maximum wear rates $\left(9.2 \times 10^{-16} \mathrm{~m}^{3} /(\mathrm{N} \cdot \mathrm{m})\right)$, whereas the wear rates of films annealed at 100, 150, 200, and $400{ }^{\circ} \mathrm{C}$ were almost the same, at approximately $4.7 \times 10^{-16} \mathrm{~m}^{3} /(\mathrm{N} \cdot \mathrm{m})$.

Lubricated with PAO + MoDTC + ZDDP, the wear rate of the $\mathrm{W}$-DLC films annealed at $25{ }^{\circ} \mathrm{C}$ was $1.48 \times 10^{-16} \mathrm{~m}^{3} /(\mathrm{N} \cdot \mathrm{m})$, which is lower than those of the annealed films shown in Fig. 3(b). Moreover, the wear rates of W-DLC films annealed at different temperatures were lower than those under PAO + MoDTC lubrication, although the wear tracks of the annealed W-DLC films still exhibited abrasive wear.
Figure 3(b) shows the wear rates of the steel balls against W-DLC films annealed at various temperatures. Based on Eq. (1), the wear volume of steel balls is related to the wear scar diameter, which is directly affected by the mechanical properties and tribochemical reaction.

\subsection{Film structure analysis}

Typical D and G peaks of the C-C bonds of DLC films could be observed in the Raman spectra, owing to the breathing mode of $A_{1 \mathrm{~g}}$ symmetry in aromatic rings and the bond stretching of $\mathrm{sp}^{2}$ atoms in both aromatic rings and chains, respectively [41]. Typical shoulder D peaks $\left(1,370-1,420 \mathrm{~cm}^{-1}\right)$ and asymmetrical G peaks $\left(1,557-1,580 \mathrm{~cm}^{-1}\right)$ of carbon crystals, as the characteristic peaks of DLC films, can be obtained [41, 42]. The increase in the $D$ peak is an indication of the state of development of the $\mathrm{sp}^{2}$ phase and indicates that the $\mathrm{sp}^{2}$ sites begin to organize into small graphitic clusters [43]. The increase in the peak intensity of the shoulder peak $\mathrm{D}$ indicates that the $\mathrm{sp}^{3}$ bond is transformed into an $\mathrm{sp}^{2}$ bond in the DLC film, indicating that the film is graphitized. Therefore, the increase in the $I_{\mathrm{D}} / I_{\mathrm{G}}$ ratio (the relative intensity ratio 
of the $D$ and $G$ peaks) and the increase in the $G$ peak position prove the graphitization of the films $[42,43]$.

\subsubsection{Unworn surfaces of W-DLC films}

The Raman spectra of W-DLC films annealed at various temperatures (within the Raman shift range of 2002,000 $\mathrm{cm}^{-1}$ ), as shown in Fig. 4(a), were analyzed using Peakfit software. Furthermore, the G peak position and $I_{\mathrm{D}} / I_{\mathrm{G}}$ ratio are shown in Fig. $4(\mathrm{~b})$. In addition, as the temperature increased, the $G$ peak position shifted from $1,557.82$ to $1,581.17 \mathrm{~cm}^{-1}$, which indicates that the disorder of the $\mathrm{C}-\mathrm{C}$ bond on the surfaces of the films was enhanced by the annealing temperature $[12,44]$. The $I_{\mathrm{D}} / I_{\mathrm{G}}$ ratios increased approximately with an increase in the annealing temperature, further confirming the graphitization of the W-DLC films. The $I_{\mathrm{D}} / I_{\mathrm{G}}$ ratios of the unannealed $\mathrm{W}$-DLC films were approximately 1.65 , and those at $100{ }^{\circ} \mathrm{C}$ increased slightly, owing to the decrease in internal stress. Meanwhile, the $I_{\mathrm{D}} / I_{\mathrm{G}}$ ratios at $400{ }^{\circ} \mathrm{C}$ decreased owing to the oxidation and carbon gasification of the W-DLC films.

\subsubsection{Worn surfaces of W-DLC films}

A random Raman spectrum (ranging from 200 to $2,000 \mathrm{~cm}^{-1}$ ) and optical images of the worn surfaces of W-DLC films annealed at various temperatures under $\mathrm{PAO}+\mathrm{MoDTC}$ and $\mathrm{PAO}+\mathrm{MoDTC}+\mathrm{ZDDP}$ lubrication are shown in Fig. 5. The middle areas of the optical images were detected by Raman spectroscopy, which
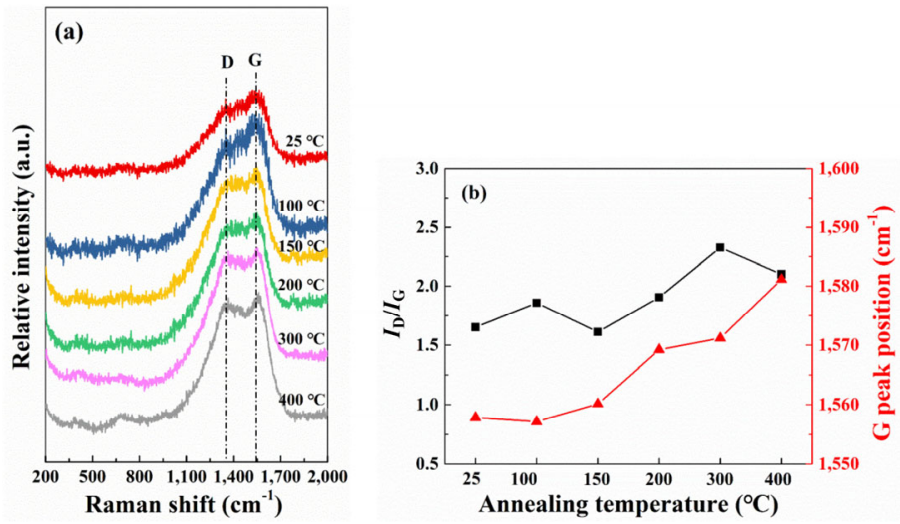

Fig. 4 (a) Raman spectra and (b) $I_{\mathrm{D}} / I_{\mathrm{G}}$ ratios on the surfaces of W-DLC films annealed at $25-400{ }^{\circ} \mathrm{C}$.
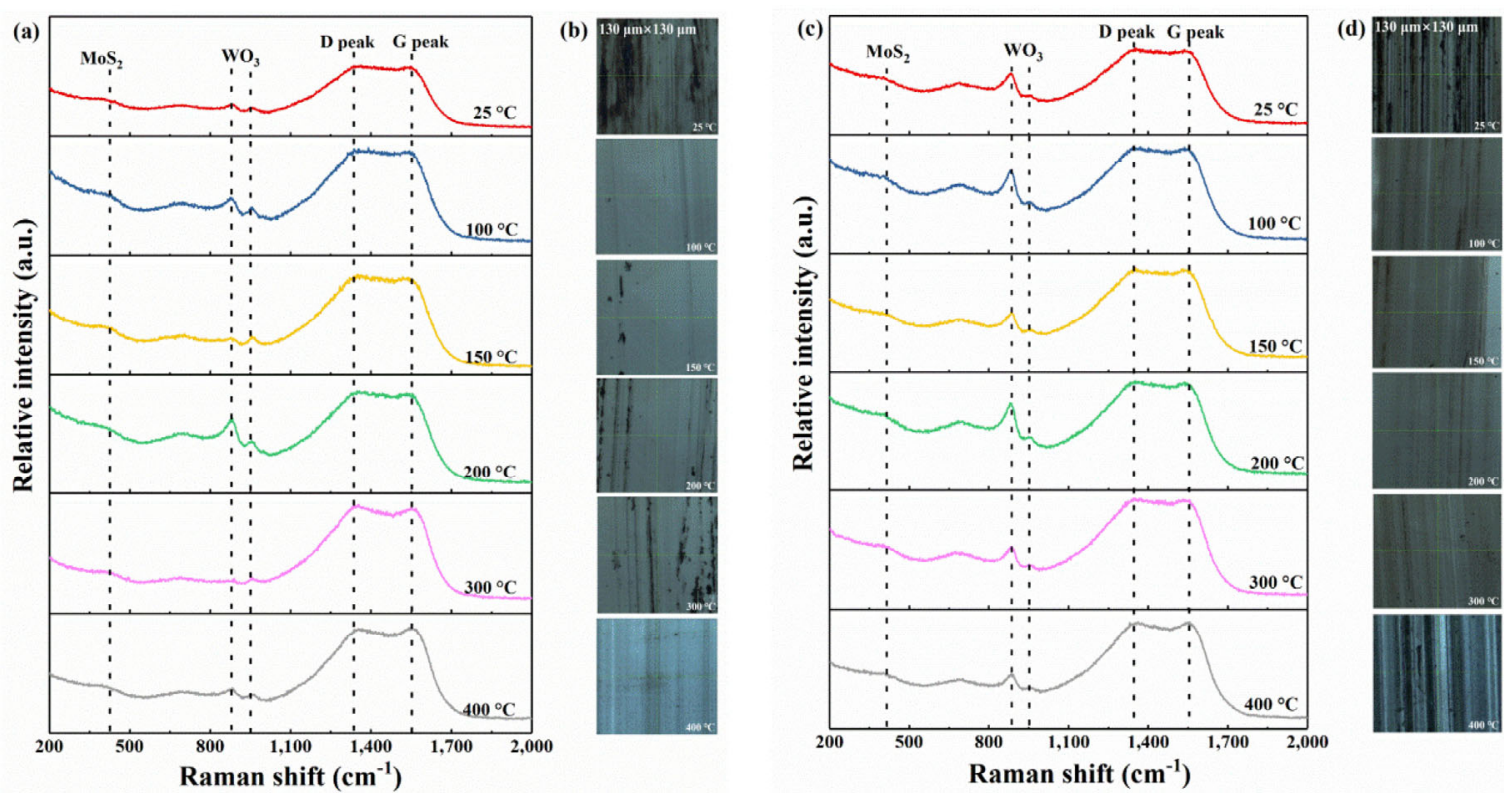

Fig. 5 Raman spectra and optical images on the worn surfaces of W-DLC films lubricated with (a, b) PAO + MoDTC and (c, d) PAO + MoDTC + ZDDP. 
are the white areas in the wear tracks. Raman peaks of tungsten oxide located at 886 and $964 \mathrm{~cm}^{-1}$ were obtained, which were the same as the Raman shift of the $\mathrm{WO}_{3}$ peak on the surfaces of W-DLC films annealed at $500{ }^{\circ} \mathrm{C}$, as shown in Section 2 [45]. As shown in Fig. 5(d), serious furrows occurred on the worn surfaces of the W-DLC films annealed at 25 and $400{ }^{\circ} \mathrm{C}$ under $\mathrm{PAO}+\mathrm{MoDTC}+\mathrm{ZDDP}$ lubrication. Figure 6 displays the $I_{\mathrm{D}} / I_{\mathrm{G}}$ ratios and $\mathrm{G}$ peak positions as a function of annealing temperature with different lubrications, as indicated in Fig. 5 . It can be observed that the $I_{\mathrm{D}} / I_{\mathrm{G}}$ ratios changed slightly, and the position of the $G$ peaks increased significantly at only 300 and $400{ }^{\circ} \mathrm{C}$ under the same lubrication conditions. This indicates that the graphitization of W-DLC films annealed at 300 and $400{ }^{\circ} \mathrm{C}$ was more serious at all temperatures.

\subsection{Chemical analysis of tribofilms}

\subsubsection{PAO + MoDTC lubrication}

Raman spectra in the typical areas (dark areas in wear tracks) of W-DLC films $\left(200-2,000 \mathrm{~cm}^{-1}\right)$ and steel balls $\left(200-2,000 \mathrm{~cm}^{-1}\right)$ lubricated with PAO + MoDTC were characterized, as shown in Fig. 7. From Fig. 7(d), it was found that dark tribofilms appeared on the worn surfaces of the steel balls against W-DLC films annealed at different temperatures under PAO + MoDTC lubrication.

$\mathrm{MoS}_{2}$ peaks have four first-order Raman active modes, which represent $E_{1 g}^{1}, E_{2 g}^{1}, E_{2 g}^{2}$ and $A_{2 g}^{1}$ [46-48]. Only two active modes can be observed here, $E_{2 \mathrm{~g}}^{1}$ and $A_{1 \mathrm{~g}}$, corresponding to the Raman peaks at 380 and $410 \mathrm{~cm}^{-1}$ on the worn surfaces of both W-DLC films
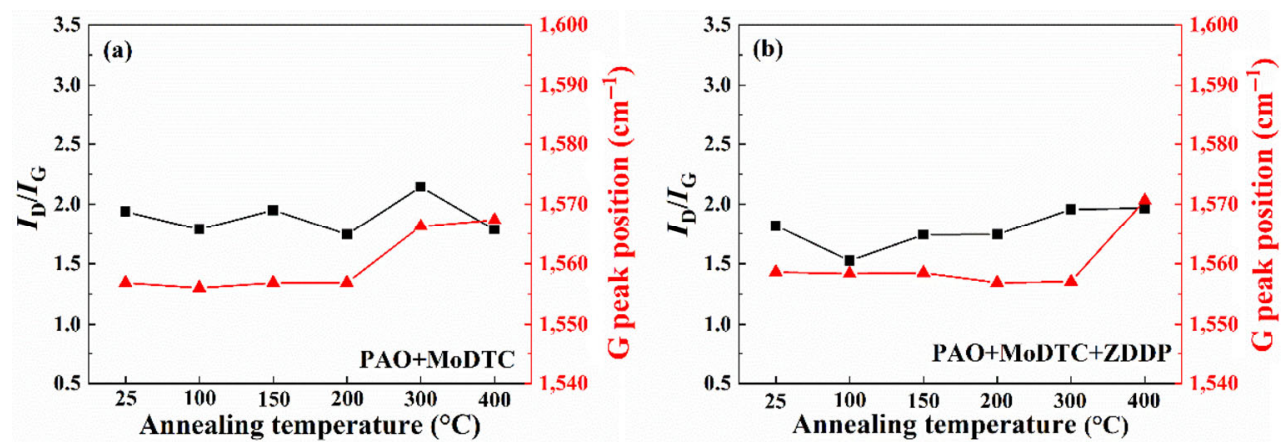

Fig. $6 I_{\mathrm{D}} / I_{\mathrm{G}}$ ratios and $\mathrm{G}$ peak position of W-DLC films as functions of annealing temperature lubricated with (a) PAO + MoDTC and (b) PAO + MoDTC + ZDDP.
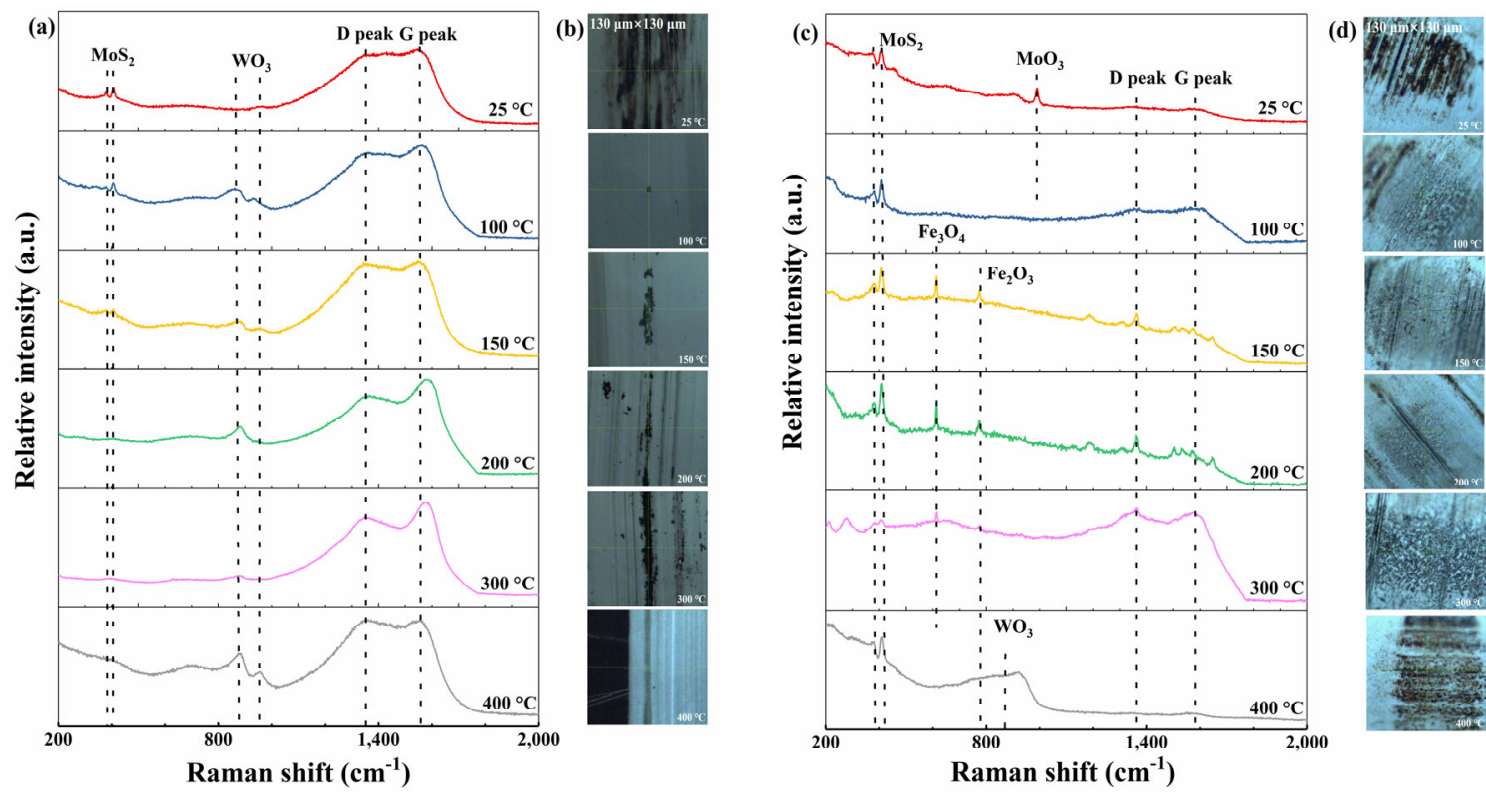

Fig. 7 Under PAO + MoDTC lubrication, Raman spectra and optical images on wear tracks of (a, b) W-DLC films and (c, d) steel balls. 
and steel balls. However, the $\mathrm{MoS}_{2}$ peak became weak when the annealing temperature was higher than $200{ }^{\circ} \mathrm{C}$. It is believed that graphitization occurred on the worn surfaces of the W-DLC film at high temperatures, and the graphite phase was easily sheared, which made $\mathrm{MoS}_{2}$ difficult to adhere to the wear tracks of the W-DLC films; thus, the $\mathrm{MoS}_{2}$ peaks on the steel balls were prominent. In addition, for the steel balls, $\mathrm{FeO}$ and $\mathrm{Fe}_{2} \mathrm{O}_{3}$ peaks appeared on the worn surfaces of the W-DLC films annealed at $150-400{ }^{\circ} \mathrm{C}$ [49], located at $775 \mathrm{~cm}^{-1}$. Furthermore, a peak was observed at $612 \mathrm{~cm}^{-1}$, which was assumed to be $\mathrm{Fe}_{3} \mathrm{O}_{4}$ [50]. Except at $400{ }^{\circ} \mathrm{C}$, obvious D and G peaks can be observed on the wear scars of the steel balls, as shown in Fig. 7(c). It is worth noting that the Raman peak of $\mathrm{MoO}_{3}$ appeared on the steel balls countered with the $\mathrm{W}$-DLC film annealed at $25^{\circ} \mathrm{C}$, located at $989 \mathrm{~cm}^{-1}$ [51]. However, it was not found on the steel balls against the W-DLC films annealed at other annealing temperatures. It should be noted that, although the intensity of the $D$ and $G$ peaks of $C-C$ bonds was weakened on the steel balls against W-DLC films annealed at $400{ }^{\circ} \mathrm{C}$, $\mathrm{WO}_{3}$ peaks appeared.

The AFM topographic images and lateral force profile of the wear surfaces of the unannealed W-DLC are shown in Fig. 8. Topographic images of AFM are shown in Fig. 8(a). The dark areas represent a low friction force in the lateral force profile, which are marked with red dotted lines. It can be observed that low-friction areas appeared in the wear tracks of the unannealed samples, whereas the heights of the corresponding morphologies were almost the same. Therefore, in combination with Figs. 7 and 8, $\mathrm{MoS}_{2}$ layers were obtained in the wear tracks of W-DLC films annealed at $25{ }^{\circ} \mathrm{C}$ [52]. However, this phenomenon was not observed on the worn surfaces of the W-DLC films annealed at other temperatures.

\subsubsection{PAO + MoDTC + ZDDP lubrication}

Under PAO + MoDTC + ZDDP lubrication, AFM morphologies of the wear tracks of W-DLC films annealed at various temperatures are as shown in Table 3, scanned by two areas $(5 \mu \mathrm{m} \times 5 \mu \mathrm{m}$ and $20 \mu \mathrm{m} \times 20 \mu \mathrm{m})$. Pad-like tribofilms were observed on the worn surfaces of the W-DLC films annealed at all annealing temperatures, which is the typical morphology of phosphate tribofilms decomposed from ZDDP + MoDTC [53-55]. In the $20 \mu \mathrm{m} \times 20 \mu \mathrm{m}$ topographies, the heights of the positions marked with a white dotted line are shown in the bottom line of Table 3. The height of the tribofilms on the worn surfaces of the W-DLC films annealed at temperatures ranging from 150 to $200{ }^{\circ} \mathrm{C}$ decreased relative to those of the unannealed samples, and the latter was more uniform than the former. It can be seen that the tribofilms on the worn surfaces of the W-DLC films annealed at $300{ }^{\circ} \mathrm{C}$ were high and uniform compared with other annealing temperatures. In the case of W-DLC films annealed at $400{ }^{\circ} \mathrm{C}$, more cracks and furrows could be obtained on the wear tracks (Fig. 2), and tribofilms of W-DLC films annealed at $400{ }^{\circ} \mathrm{C}$ grew higher and more compact on the cracks and furrows than those at other regions, because more stresses emerged near the cracks and furrows.

Figure 9 presents the Raman spectra of W-DLC film discs $\left(200-2,000 \mathrm{~cm}^{-1}\right)$ and steel balls $\left(200-2,000 \mathrm{~cm}^{-1}\right)$, as well as the optical images of the corresponding areas under PAO + MoDTC + ZDDP lubrication. Except for
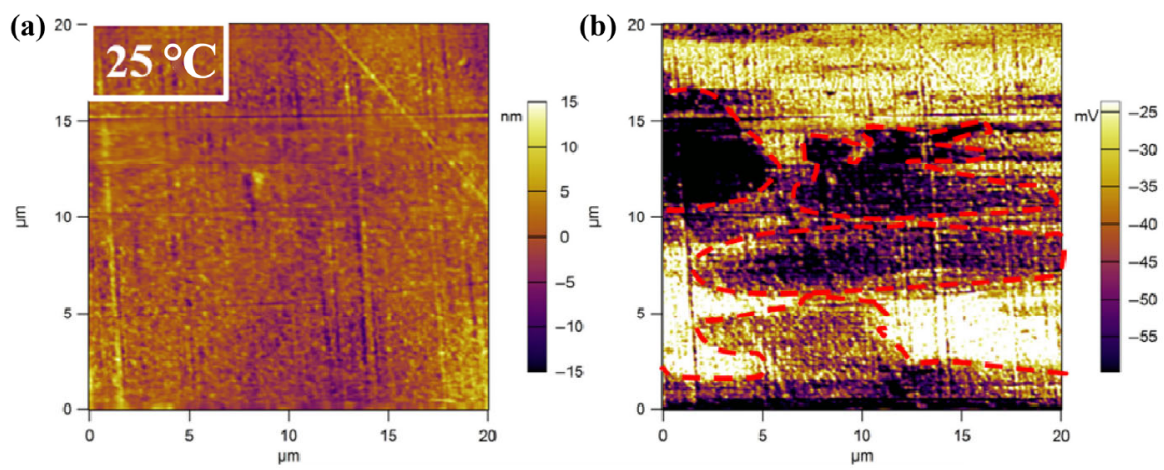

Fig. 8 Under PAO + MoDTC lubrication, (a) topographic images and (b) lateral force profile on the wear tracks of W-DLC annealed at $25{ }^{\circ} \mathrm{C}$. 
Table 3 Under PAO+MoDTC+ZDDP lubrication, AFM images of wear tracks of W-DLC films annealed at all temperatures.

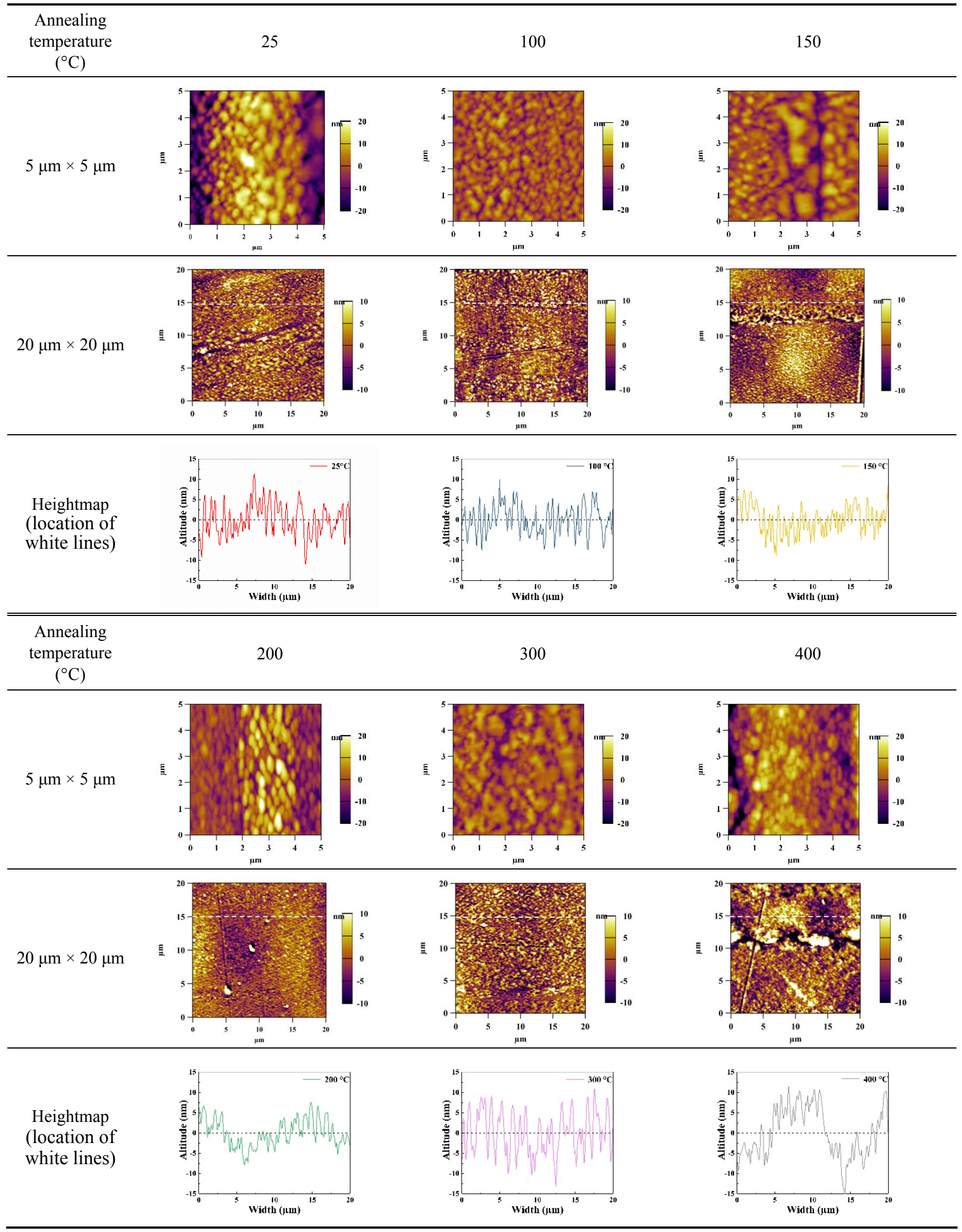



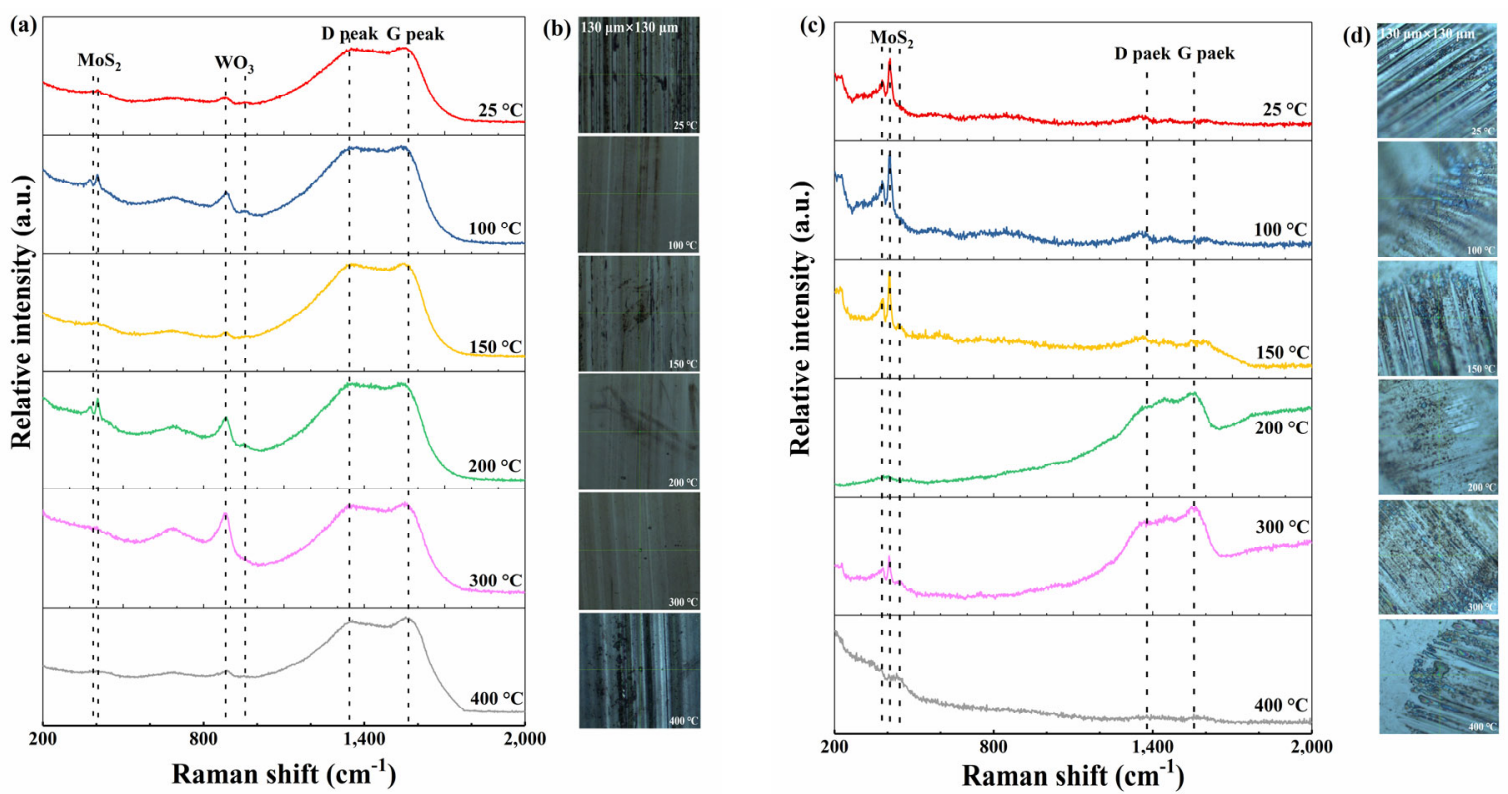

Fig. 9 Under PAO + MoDTC + ZDDP lubrication, Raman spectra and optical images of wear tracks of (a, b) W-DLC films and (c, d) steel balls.

the obvious D and $\mathrm{G}$ peaks of the $\mathrm{C}-\mathrm{C}$ bonds, $\mathrm{MoS}_{2}$ peaks were observed on the worn surfaces of the W-DLC films, the positions (380 and $410 \mathrm{~cm}^{-1}$ ) of which were the same as those under PAO + MoDTC lubrication. In addition, the $\mathrm{MoS}_{2}$ peak on the steel balls located at $450 \mathrm{~cm}^{-1}$ represented the Mo-S bond in the $A_{1 g}$ vibration mode of $\mathrm{MoS}_{2}$ [36]. It should be noted that the intensities of the $\mathrm{MoS}_{2}$ peaks, D peaks, and $G$ peaks of the steel ball against the W-DLC films annealed at $400{ }^{\circ} \mathrm{C}$ were lower than those of the other annealing temperatures. Figure 10 shows the SEM morphologies and EDS analysis of the characteristic locations of the steel balls compared with W-DLC films annealed at 25,200 , and $400{ }^{\circ} \mathrm{C}$, which were similar to those of the samples annealed at other temperatures. The tribofilms on the worn surfaces of all steel balls were almost the same and were composed of carbon, zinc, sulfur, phosphorus, and molybdenum. However, obvious sulfur and phosphorus could be found in the EDS spectra of the steel balls in comparison with W-DLC films annealed at $400{ }^{\circ} \mathrm{C}$; however, the intensities of sulfide peaks were not obvious in the Raman spectra. It is generally believed that sulfide exists in the lower layer of phosphate. Furthermore, phosphate was shown to protect $\mathrm{MoS}_{2}$ under MoDTC + ZDDP lubrication in previous studies [56]. However, the feedback of phosphate was weaker than that of sulfide in the Raman spectra, leading to a lower peak intensity of sulfide. Another possible reason for this phenomenon is that sulfur comes from sulfate, an intermediate product of ZDDP decomposition [57].

\section{Discussion}

Under PAO + MoDTC and PAO + MoDTC + ZDDP lubrications, the $I_{\mathrm{D}} / I_{\mathrm{G}}$ ratios and $\mathrm{G}$ peak positions of W-DLC films with different annealing temperatures changed little compared with the unworn surfaces, as shown in Figs. 4 and 6. The annealing treatment reduced the internal stresses of the W-DLC films and converted the $\mathrm{C}-\mathrm{C}$ bond from $\mathrm{sp}^{3}$ into $\mathrm{sp}^{2}$; however, the friction processes cannot provide sufficient energy to further graphitize the W-DLC films.

As a hard film, a DLC film is easy to exfoliate owing to its high internal stress. Therefore, abrasive wear was the main wear mechanism. Under PAO lubrication, optical images of the worn surface are shown in Fig. S1 in the Electronic Supplementary Material (ESM). Obvious spalling occurred in the wear tracks of the films annealed at 25,300 , and $400{ }^{\circ} \mathrm{C}$, as marked in red. The spalling on the worn surfaces of the W-DLC films annealed at $25{ }^{\circ} \mathrm{C}$ is due to the high internal stress. Although the average COF of the samples annealed at $300{ }^{\circ} \mathrm{C}$ was lower due to the interaction of 

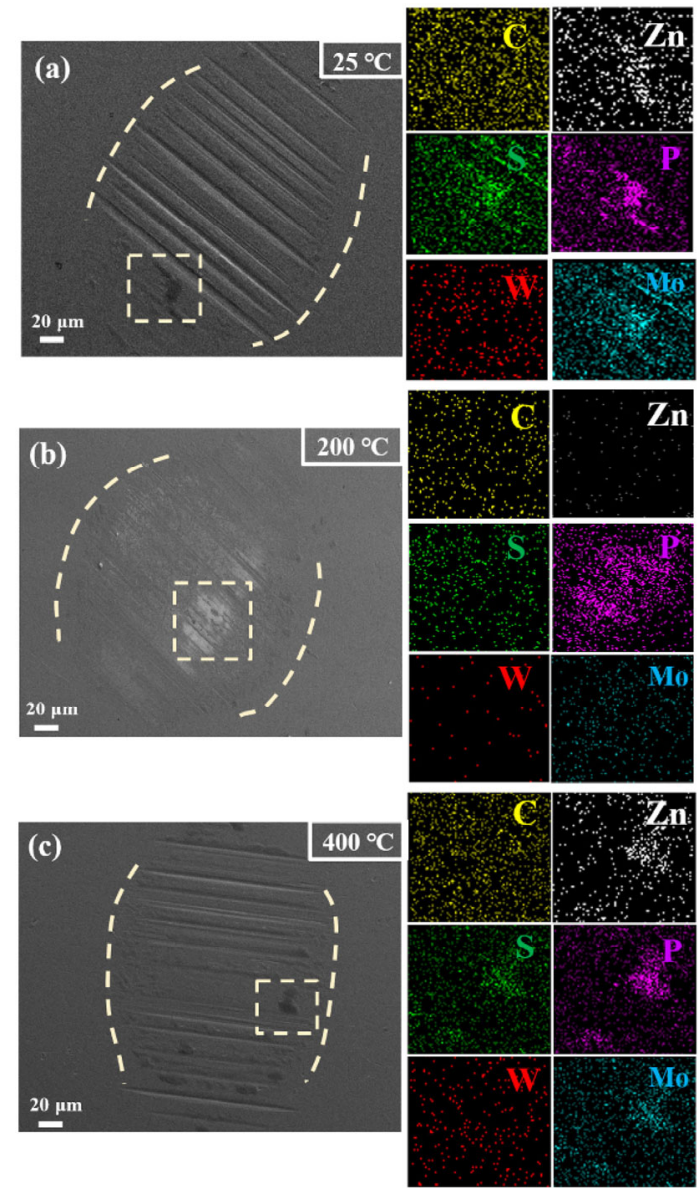

Fig. 10 Under PAO + MoDTC + ZDDP lubrication, SEM morphologies of wear scars on the steel balls countered with W-DLC films annealed at (a) $25^{\circ} \mathrm{C}$, (b) $200{ }^{\circ} \mathrm{C}$, and (c) $400{ }^{\circ} \mathrm{C}$.

graphite carbon and abrasive particles, the hardness and plastic resistance of the annealed W-DLC films decreased with an increase in the annealing temperatures reflected by $H / E$ and $H^{3} / E^{2}$. Thus, spalling occurred on the worn surfaces of the W-DLC films annealed at 300 and $400{ }^{\circ} \mathrm{C}$.

Under the PAO + MoDTC lubrication, $\mathrm{MoS}_{2}$ decomposed by MoDTC achieves a good lubrication performance and plays a role in reducing friction with the combined effect of temperature and shear stress. The tribochemical reaction process of MoDTC is generally considered to be divided into three stages: (1) the formation of nitrogen-containing substances to protect the surface from wear, (2) the formation of Mo oxides, and (3) the formation of $\mathrm{MoS}_{2}$ and Mo oxides. As hard particles, Mo oxides form abrasive wear on the worn surface [57]. However, compared with the optical images on the worn surfaces of W-DLC films annealed at different temperatures under PAO + MoDTC lubrication (Fig. 5(b)), it can be seen that the abrasive wear significantly decreased, particularly for the samples annealed at $400{ }^{\circ} \mathrm{C}$. MoDTC cannot only reduce the $\mathrm{COF}$, it also alleviates the spalling of annealed W-DLC films, which is inconsistent with the general phenomenon of friction and wear behaviors of DLC films lubricated using MoDTC.

It should be noted that $\mathrm{WO}_{3}$ peaks appeared on the worn surfaces of W-DLC films annealed at different temperatures under $\mathrm{PAO}+\mathrm{MoDTC}$ and $\mathrm{PAO}+$ MoDTC + ZDDP lubrication. However, under PAO and $\mathrm{PAO}+\mathrm{ZDDP}$ lubrication, no $\mathrm{WO}_{3}$ peaks emerged on the worn surfaces of any samples (Raman spectrum of a worn surface under PAO and PAO + ZDDP lubrication is shown in Fig. S2 in the ESM). This is due to the formation of oxide by the reaction products of MoDTC and is not due to oxidation during friction. The $\mathrm{W}-\mathrm{O}$ bond energy (35.7 and $38.0 \mathrm{eV}$ ) is lower than the Mo-O bond energy (228.1 and $231.2 \mathrm{eV}$ ) [25], and thus $\mathrm{WO}_{3}$ is easier to produce. However, unlike $\mathrm{MoO}_{3}, \mathrm{WO}_{3}$ has lubricity and interacts with $\mathrm{MoS}_{2}$ and graphite carbon, which can further remove the abrasive particles and reduce wear.

\subsection{PAO + MoDTC lubrication}

Under PAO + MoDTC lubrication, except at $300{ }^{\circ} \mathrm{C}$, the typical phenomenon of increasing the wear rates did not occur on the W-DLC films annealed at other temperatures, which was higher than that of the unannealed films. According to Figs. 7 and 8, $\mathrm{MoS}_{2}$ layers and Raman peaks of $\mathrm{MoO}_{3}$ appeared on the worn surfaces of the unannealed W-DLC films and their counter bodies. However, this phenomenon was not observed in the samples annealed at other temperatures. This may be because the surface graphitization of the samples occurred with an increase in the annealing temperature, which was conducive to the removal of wear particles on the worn surfaces. When the annealing temperature was lower than $300{ }^{\circ} \mathrm{C}$, the $\mathrm{D}$ and $\mathrm{G}$ peaks of the carbon bond, $\mathrm{MoS}_{2}$, and $\mathrm{WO}_{3}$ peaks were observed by combining the Raman spectra of the worn surfaces of the W-DLC films and steel balls. Therefore, under PAO + MoDTC lubrication, the lubrication mechanism was the interactive lubrication of graphitized carbon, $\mathrm{WO}_{3}$, 
and $\mathrm{MoS}_{2}$. In addition, it was indicated that W-DLC films annealed at $300{ }^{\circ} \mathrm{C}$ were heavily graphitized (the relative intensities of the D and $G$ peaks of steel balls were greater) compared with other temperatures, resulting in the lowest COFs. However, graphite carbon was easily removed, and thus the wear rates of W-DLC films annealed at $300{ }^{\circ} \mathrm{C}$ were increased under PAO + MoDTC lubrication. Oxygen appeared on the surface of W-DLC films annealed at $400{ }^{\circ} \mathrm{C}$ (detected by EDS spectra in Section 2); however, the typical $D$ and $G$ peaks on the steel balls were not obvious at $400{ }^{\circ} \mathrm{C}$, whereas the Raman peaks of $\mathrm{WO}_{3}$ were prominent under PAO + MoDTC lubrication. Therefore, it can be seen that $\mathrm{WO}_{3}$ and $\mathrm{MoS}_{2}$ played a dominant role in the lubrication of W-DLC films annealed at $400{ }^{\circ} \mathrm{C}$. $\mathrm{WO}_{3}$ has a crystalline structure, and its lubrication performance is not as good as that of graphite carbon and $\mathrm{MoS}_{2}$ [12]. Therefore, under $\mathrm{PAO}+\mathrm{MoDTC}$ lubrication, the COFs and wear rates of W-DLC films annealed at $400{ }^{\circ} \mathrm{C}$ were similar to those of films annealed at 150 and $200{ }^{\circ} \mathrm{C}$. However, under PAO + MoDTC lubrication, the degree of graphitization and oxidation of the unannealed W-DLC films were not relatively light during the friction process. The relative intensities of the $\mathrm{D}, \mathrm{G}$, and $\mathrm{WO}_{3}$ peaks of the steel balls were low, compared with temperatures of $100-300{ }^{\circ} \mathrm{C}$, leading to higher COFs, the better mechanical properties, and higher wear resistance.

\subsection{PAO + MoDTC + ZDDP lubrication}

Under PAO + MoDTC + ZDDP lubrication, typical D and $G$ peaks appeared on all wear scars of the steel balls. The relative intensities of the D and G peaks of the steel balls countered with W-DLC films annealed at $400{ }^{\circ} \mathrm{C}$ were lower, but those at 150,200 , and $300{ }^{\circ} \mathrm{C}$ were higher. Meanwhile, pad-like tribofilms were detected on the worn surfaces of the W-DLC films, and the compositions of the tribofilms on both the counter bodies were similar. Therefore, the COFs of the W-DLC films annealed at different temperatures were almost the same. Under the PAO + MoDTC + ZDDP lubrication, the tribological mechanism was the interaction between graphitized carbon, $\mathrm{MoS}_{2}$, $\mathrm{WO}_{3}$, and pad-like phosphate. The tribofilms on the surfaces of the W-DLC films grew more uniform and compact (the tribofilms on the worn surfaces of W-DLC films annealed at 25,200 , and $400{ }^{\circ} \mathrm{C}$ under $\mathrm{PAO}+\mathrm{ZDDP}$ lubrication, as shown in Table S1 in the ESM), and it can be seen that MoDTC and ZDDP effectively promoted tribochemical interactions to achieve better anti-wear tribofilm growth [26-30,53]. Annealing affected the formation of pad-like phosphate, particularly at 150 and $200{ }^{\circ} \mathrm{C}$. However, the phosphate tribofilms grown on the worn surfaces of the W-DLC films annealed at $300{ }^{\circ} \mathrm{C}$ were obviously better than those annealed at the two temperatures. The hardness of the W-DLC films annealed at $300{ }^{\circ} \mathrm{C}$ decreased, and thus cracks and other damage were more likely to occur at the early stage of friction and wear behaviors (the optical images of the wear tracks of W-DLC films annealed at different temperatures under PAO lubrication are shown in Fig. S1 in the ESM), promoting the formation of the phosphate structure owing to the high contact stress [58,59]. When the annealing temperature was increased to $400{ }^{\circ} \mathrm{C}$, the hardness of the W-DLC films further declined, and obvious furrows and plastic deformations appeared on the worn surfaces, causing the tribofilms to concentrate near the furrows owing to high contact stress. The decrease in the mechanical properties and uneven tribofilms led to an increase in the wear rate of the W-DLC films annealed at $400{ }^{\circ} \mathrm{C}$, compared with the samples annealed at $300{ }^{\circ} \mathrm{C}$. It was suggested that the addition of ZDDP provided sulfur to promote the formation of $\mathrm{MoS}_{2}$ or to protect $\mathrm{MoS}_{2}$ from oxidation [56, 59-61]. However, it was observed that the relative contents of $\mathrm{MoS}_{2}$ and carbon bonds on the worn surfaces of W-DLC films annealed at various temperatures and their counter bodies did not increase or even decrease after adding ZDDP, as shown in Figs. 7 and 9. Metal sulfide, the base of phosphate tribofilms, is close to the surface of counter bodies [54, 56, 61,]; therefore, Raman spectra showed that the relative content of $\mathrm{MoS}_{2}$ was lower.

Furthermore, under the PAO + MoDTC + ZDDP conditions, the depths of the wear tracks and wear rates of the W-DLC films were significantly reduced owing to the anti-wear effect of ZDDP. Compared with PAO lubrication, the COFs of samples annealed at different temperatures decreased under PAO + MoDTC and PAO + MoDTC + ZDDP lubrications, 
particularly at 100,150 , and $400{ }^{\circ} \mathrm{C}$. Overall, the friction and wear properties of W-DLC films annealed at 25 and $100{ }^{\circ} \mathrm{C}$ were better than those of the films lubricated with PAO + MoDTC and PAO + MoDTC + ZDDP.

\section{Conclusions}

The interactions between annealed W-DLC films, MoDTC, and MoDTC + ZDDP were studied, and the main conclusions are as follows:

1) Under $\mathrm{PAO}+\mathrm{MoDTC}$ lubrication, $\mathrm{MoS}_{2}$ and $\mathrm{WO}_{3}$ were produced on the W-DLC film surfaces owing to the addition of MoDTC, which led to a decrease in COF. The COF of W-DLC films annealed at $100-300{ }^{\circ} \mathrm{C}$ was lower than that of the unannealed samples, whereas the intensity of the $\mathrm{C}-\mathrm{C}$ bond Raman peak of the former was higher than that of the latter. When the W-DLC films were annealed at $25-400{ }^{\circ} \mathrm{C}$ and lubricated with MoDTC, the lubrication mechanism was the interaction of graphite carbon, $\mathrm{MoS}_{2}$, and $\mathrm{WO}_{3}$. When the annealing temperature was $300{ }^{\circ} \mathrm{C}$, the peak strengths of $\mathrm{D}$ and $\mathrm{G}$ were relatively high, which led to the minimum $\mathrm{COF}$ and maximum wear rate.

However, $\mathrm{WO}_{3}$ and $\mathrm{MoS}_{2}$ play a leading role in the lubrication mechanism of W-DLC films annealed at $400{ }^{\circ} \mathrm{C}$

2) Under PAO + MoDTC + ZDDP lubrication, the $\mathrm{COF}$ of $\mathrm{W}$-DLC films at all annealing temperatures were almost the same, whereas wear rates decreased dramatically compared with MoDTC lubrication for phosphate tribofilms. The tribofilms of W-DLC films annealed at $300{ }^{\circ} \mathrm{C}$ were higher and more compact compared with those of the samples annealed at other temperatures.

\section{Acknowledgements}

This research was financially supported by the National Natural Science Foundation of China (Nos. 51875537 and 41872183), the Pre-Research Program in National 14th Five-Year Plan (No. 61409230614) and the Fundamental Research Funds for the Central University (No. 2652018094).

Electronic Supplementary Material Supplementary material is available in the online version of this article at https://doi.org/10.1007/s40544-021-0514-4.

Open Access This article is licensed under a Creative Commons Attribution 4.0 International License, which permits use, sharing, adaptation, distribution and reproduction in any medium or format, as long as you give appropriate credit to the original author(s) and the source, provide a link to the Creative Commons licence, and indicate if changes were made.

The images or other third party material in this article are included in the article's Creative Commons licence, unless indicated otherwise in a credit line to the material. If material is not included in the article's Creative Commons licence and your intended use is not permitted by statutory regulation or exceeds the permitted use, you will need to obtain permission directly from the copyright holder.

To view a copy of this licence, visit http://creativecommons.org/licenses/by/4.0/.

\section{References}

[1] Vetter J. 60 years of DLC coatings: Historical highlights and technical review of cathodic arc processes to synthesize various DLC types, and their evolution for industrial applications. Surf Coat Technol 257: 213-240 (2014)

[2] Fan X Q, Xue Q J, Wang L P. Carbon-based solid-liquid lubricating coatings for space applications-A review. Friction 3(3): 191-207 (2015)

[3] Robertson J. Diamond-like amorphous carbon. Mater Sci Eng: R: Rep 37(4-6): 129-281 (2002)

[4] Grill A. Diamond-like carbon: State of the art. Diam Relat Mater 8(2-5): 428-434 (1999)

[5] Ni W Y, Cheng Y T, Weiner A M, Perry T A. Tribological behavior of diamond-like-carbon (DLC) coatings against aluminum alloys at elevated temperatures. Surf Coat Technol 201(6): 3229-3234 (2006)

[6] Bhowmick S, Banerji A, Khan M Z U, Lukitsch M J, Alpas A T. High temperature tribological behavior of tetrahedral amorphous carbon (ta-C) and fluorinated ta-C coatings against aluminum alloys. Surf Coat Technol 284: 14-25 (2015)

[7] Konca E, Cheng Y T, Weiner A M, Dasch J M, Alpas A T. Elevated temperature tribological behavior of non-hydrogenated diamond-like carbon coatings against 319 aluminum alloy. Surf Coat Technol 200(12-13): 3996-4005 (2006) 
[8] Dai, M J, Wei, C B, Zhou, K S, Zhu, M, Lin, S S, Hou, $\mathrm{H}$ J, Shi, Q. Influence of annealing temperature on microstructuresand tribological behavior of W-doped diamond-like-carbon coatings. Chin J Vac Sci Technol 36(10): 1112-1118 (2016) (in Chinese)

[9] Alessandretti G C, Violino P. Thermometry by CARS in an automobile engine. J Phys D: Appl Phys 16(9): 1583-1594 (1983)

[10] Zheng J B, Wang J H, Zhao Z B, Wang D D, Huang Z H. Effect of equivalence ratio on combustion and emissions of a dual-fuel natural gas engine ignited with diesel. Appl Therm Eng 146: 738-751 (2019)

[11] Blok H. The flash temperature concept. Wear 6(6): 483-494 (1963)

[12] Li W M, Kumara C, Luo H M, Meyer H M, He X, Ngo D, Kim S H, Qu J. Ultralow boundary lubrication friction by three-way synergistic interactions among ionic liquid, friction modifier, and dispersant. ACS Appl Mater Interfaces 12(14): 17077-17090 (2020)

[13] Gharam A A, Lukitsch M J, Balogh M P, Irish N, Alpas A T. High temperature tribological behavior of W-DLC against aluminum. Surf Coat Technol 206(7): 1905-1912 (2011)

[14] Banerji A, Bhowmick S, Alpas A T. High temperature tribological behavior of $\mathrm{W}$ containing diamond-like carbon (DLC) coating against titanium alloys. Surf Coat Technol 241: 93-104 (2014)

[15] Bhowmick S, Lou M, Khan M Z U, Banerji A, Alpas A T. Role of an oxygen atmosphere in high temperature sliding behaviour of $\mathrm{W}$ containing diamond-like carbon (W-DLC). Surf Coat Technol 332: 399-407 (2017)

[16] Etsion I, Halperin G, Becker E. The effect of various surface treatments on piston pin scuffing resistance. Wear 261(7-8): 785-791 (2006)

[17] Gåhlin R, Larsson M, Hedenqvist P. ME-C: H coatings in motor vehicles. Wear 249(3-4): 302-309 (2001)

[18] Kato S, Sasaki S. Effects of hydraulic oil and lubricant additives on dynamic friction properties under various reciprocating sliding conditions. Friction 8(2): 471-480 (2020)

[19] Liu K, Kang J J, Zhang G G, Lu Z B, Yue W. Effect of temperature and mating pair on tribological properties of DLC and GLC coatings under high pressure lubricated by MoDTC and ZDDP. Friction 9(6): 1390-1405 (2020)

[20] Morina A, Neville A, Priest M, Green J H. ZDDP and MoDTC interactions in boundary lubrication - The effect of temperature and ZDDP/MoDTC ratio. Tribol Int 39(12): 1545-1557 (2006)
[21] Graham J, Spikes H, Korcek S. The friction reducing properties of molybdenum dialkyldithiocarbamate additives: Part I-factors influencing friction reduction. Tribol Trans 44(4): 626-636 (2001)

[22] Yue W, Fu Z Q, Wang S, Gao X C, Huang H P, Liu J J. Tribological synergistic effects between plasma nitrided 52100 steel and molybdenum dithiocarbamates additive in boundary lubrication regime. Tribol Int 74: 72-78 (2014)

[23] Yue W, Liu C Y, Fu Z Q, Wang C B, Huang H P, Liu J J. Effects of tungsten doping contents on tribological behaviors of tungsten-doped diamond-like carbon coatings lubricated by MoDTC. Tribol Lett 58(2): 31 (2015)

[24] Espejo C, Thiébaut B, Jarnias F, Wang C, Neville A, Morina A. MoDTC tribochemistry in steel/steel and steel/diamondlike-carbon systems lubricated with model lubricants and fully formulated engine oils. J Tribol 141(1): 012301 (2019)

[25] Zhang S J, Yue W, Kang J J, Wang Y Y, Fu Z Q, Zhu L N, She D S, Wang C B. Ti content on the tribological properties of W/Ti-doped diamond-like carbon film lubricating with additives. Wear 430-431: 137-144 (2019)

[26] Okubo H, Sasaki S. In situ Raman observation of structural transformation of diamond-like carbon films lubricated with MoDTC solution: Mechanism of wear acceleration of DLC films lubricated with MoDTC solution. Tribol Int 113: 399-410 (2017)

[27] De Feo M, de Barros Bouchet M I, Minfray C, Esnouf C, Le Mogne T, Meunier F, Yang L, Thiebaut B, Pavan S, Martin J M. Formation of interfacial molybdenum carbide for DLC lubricated by MoDTC: Origin of wear mechanism. Wear 370-371: 17-28 (2017)

[28] Kassim K A M, Tokoroyama T, Murashima M, Umehara N. The wear classification of MoDTC-derived particles on silicon and hydrogenated diamond-like carbon at room temperature. Tribol Int 147: 106176 (2020)

[29] Vengudusamy B, Green J H, Lamb G D, Spikes H A. Behaviour of MoDTC in DLC/DLC and DLC/steel contacts. Tribol Int 54: 68-76 (2012)

[30] Kosarieh S, Morina A, Flemming J, Lainé E, Neville A. Wear mechanisms of hydrogenated DLC in oils containing MoDTC. Tribol Lett 64(1): 4 (2016)

[31] Martin J M, Grossiord C, Varlot K, Vacher B, Igarashi J. Synergistic effects in binary systems of lubricant additives: A chemical hardness approach. Tribol Lett 8(4): 193-201 (2000)

[32] Bec S, Tonck A, Georges J M, Roper G W. Synergistic effects of MoDTC and ZDTP on frictional behaviour of tribofilms at the nanometer scale. Tribol Lett 17(4): 797-809 (2004) 
[33] Masuko M, Ono T, Aoki S, Suzuki A, Ito H. Friction and wear characteristics of DLC coatings with different hydrogen content lubricated with several Mo-containing compounds and their related compounds. Tribol Int 82: 350-357 (2015)

[34] Al-Jeboori Y, Kosarieh S, Morina A, Neville A. Investigation of pure sliding and sliding/rolling contacts in a DLC/Cast iron system when lubricated in oils containing MoDTC-Type friction modifier. Tribol Int 122: 23-37 (2018)

[35] de Barros M I, Bouchet J, Raoult I, Le Mogne T, Martin J M, Kasrai M, Yamada Y. Friction reduction by metal sulfides in boundary lubrication studied by XPS and XANES analyses. Wear 254(9): 863-870 (2003)

[36] Windom B C, Sawyer W G, Hahn D W. A Raman spectroscopic study of $\mathrm{MoS}_{2}$ and $\mathrm{MoO}_{3}$ : Applications to tribological systems. Tribol Lett 42(3): 301-310 (2011)

[37] Xu D C, Wang C, Espejo C, Wang J G, Neville A, Morina A. Understanding the friction reduction mechanism based on molybdenum disulfide tribofilm formation and removal. Langmuir 34(45): 13523-13533 (2018)

[38] Yue W, Wang S, Fu Z Q, Gao X C, Yu X, Liu J J. Influence of $\mathrm{W}$ content on microstructural, mechanical and tribological properties of sulfurized W-doped diamond-like carbon coatings. Surf Coat Technol 218: 47-56 (2013)

[39] Vengudusamy B, Green J H, Lamb G D, Spikes H A. Influence of hydrogen and tungsten concentration on the tribological properties of DLC/DLC contacts with ZDDP. Wear 298-299: 109-119 (2013)

[40] Fu Z Q, Wang C B, Zhang W, Wang W, Yue W, Yu X, Peng Z J, Lin S S, Dai M J. Influence of W content on tribological performance of $\mathrm{W}$-doped diamond-like carbon coatings under dry friction and polyalpha olefin lubrication conditions. Mater Des 51: 775-779 (2013)

[41] Qiang L, Gao K X, Zhang L F, Wang J, Zhang B, Zhang J Y. Further improving the mechanical and tribological properties of low content Ti-doped DLC film by W incorporating. Appl Surf Sci 353: 522-529 (2015)

[42] Ferrari A C, Robertson J. Raman spectroscopy of amorphous, nanostructured, diamond-like carbon, and nanodiamond. Philos Trans A Math Phys Eng Sci 362(1824): 2477-2512 (2004)

[43] Ferrari A C, Robertson J. Interpretation of Raman spectra of disordered and amorphous carbon. Phys Rev B 61(20): 14095-14107 (2000)

[44] Ferrari A C, Kleinsorge B, Morrison N A, Hart A, Stolojan $\mathrm{V}$, Robertson J. Stress reduction and bond stability during thermal annealing of tetrahedral amorphous carbon. $J$ Appl Phys 85(10): $7191-7197$ (1999)
[45] Boulova M, Lucazeau G. Crystallite nanosize effect on the structural transitions of $\mathrm{WO}_{3}$ studied by Raman spectroscopy. J Solid State Chem 167(2): 425-434 (2002)

[46] Viršek M, Jesih A, Milošević I, Damnjanović M, Remškar M. Raman scattering of the $\mathrm{MoS}_{2}$ and $\mathrm{WS}_{2}$ single nanotubes. Surf Sci 601(13): 2868-2872 (2007)

[47] Khaemba D N, Neville A, Morina A. New insights on the decomposition mechanism of Molybdenum DialkyldiThioCarbamate (MoDTC): A Raman spectroscopic study. RSC $A d v$ 6(45): 38637-38646 (2016)

[48] Yang L Q, Neville A, Brown A, Ransom P, Morina A. Friction reduction mechanisms in boundary lubricated W-doped DLC coatings. Tribol Int 70: 26-33 (2014)

[49] Zahid R, Hassan M B H, Alabdulkarem A, Varman M, Mufti R A, Kalam M A, Zulkifli N W B M, Gulzar M, Lee T. Investigation of the tribochemical interactions of a tungstendoped diamond-like carbon coating (W-DLC) with formulated palm trimethylolpropane ester (TMP) and polyalphaolefin (PAO). RSC Adv 7(43): 26513-26531 (2017)

[50] Shebanova O N, Lazor P. Raman study of magnetite $\left(\mathrm{Fe}_{3} \mathrm{O}_{4}\right)$ : Laser-induced thermal effects and oxidation. $J$ Raman Spectrosc 34(11): 845-852 (2003)

[51] Khaemba D N, Neville A, Morina A. A methodology for Raman characterisation of MoDTC tribofilms and its application in investigating the influence of surface chemistry on friction performance of MoDTC lubricants. Tribol Lett 59(3): 38 (2015)

[52] Huang P, Castellanos-Gomez A, Guo D, Xie G X, Li J. Frictional characteristics of suspended $\mathrm{MoS}_{2} . J$ Phys Chem C 122(47): 26922-26927 (2018)

[53] Nicholls M A, Do T, Norton P R, Kasrai M, Bancroft G M. Review of the lubrication of metallic surfaces by zinc dialkyl-dithiophosphates. Tribol Int 38(1): 15-39 (2005)

[54] Spikes H. The history and mechanisms of ZDDP. Tribol Lett 17(3): 469-489 (2004)

[55] Gosvami N N, Bares J A, Mangolini F, Konicek A R, Yablon D G, Carpick R W. Mechanisms of antiwear tribofilm growth revealed in situ by single-asperity sliding contacts. Science 348(6230): 102-106 (2015)

[56] Zhang J, Spikes H. On the mechanism of ZDDP antiwear film formation. Tribol Lett 63(2): 1-15 (2016)

[57] Morina A, Neville A. Tribofilms: aspects of formation, stability and removal. J Phys D: Appl Phys 40(18): 5476-5487 (2007)

[58] Gosvami N N, Ma J, Carpick R W. An in situ method for simultaneous friction measurements and imaging of interfacial tribochemical film growth in lubricated contacts. Tribol Lett 66(4): 154 (2018) 
[59] Wang Y Y, Yue W, Kang J J, Zhu L N, Fu Z Q, Wang C B. Effect of surface nanocrystallization pretreatment on the tribological properties of plasma nitrided AISI 316L stainless steel under boundary lubrication. J Tribol 141(4): 042102 (2018)

[60] Martin J M, Grossiord C, Le Mogne T, Igarashi J. Transfer

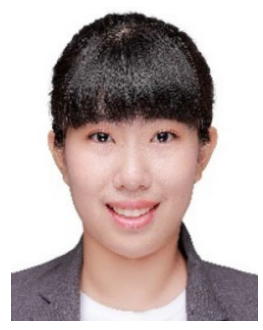

Shaojun ZHANG. She got her M.S. degree in mechanical engineering in 2020 at China University of

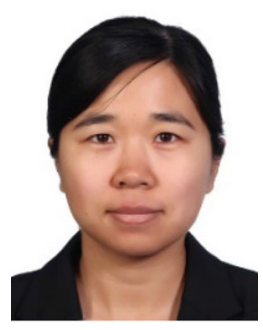

Lina ZHU. She got her Ph.D. degree in 2014 at China University of Geosciences (Beijing). She is an associate professor at China

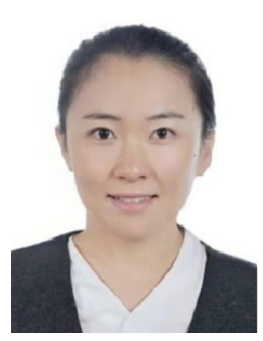

Yanyan WANG. She got her Ph.D. degree in 2021 at China University

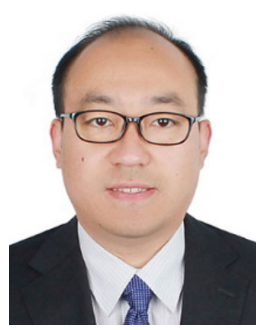

Jiajie KANG. He got his Ph.D. degree in 2013 at China University of Geosciences (Beijing). He is a professor at China University of Geosciences (Beijing). He has films and friction under boundary lubrication. Wear 245(1-2): 107-115 (2000)

[61] Onodera T, Martin J M, Minfray C, Dassenoy F, Miyamoto A. Antiwear chemistry of ZDDP: Coupling classical MD and tight-binding quantum chemical MD methods (TB-QCMD). Tribol Lett 50(1): 31-39 (2013)

Geosciences (Beijing). After then, she became a Ph.D. student at the same university. Her research interests include lubricating additives and carbon-based films.

University of Geosciences (Beijing). She has authored or co-authored more than 80 journal papers. Her research interests are lubricating additives and surface engineering.

of Geosciences (Beijing). Her research interests include lubricating additives and carbon-based films.

authored or co-authored more than 100 journal papers. His research interests are lubricating additives and thermal spray coatings. 


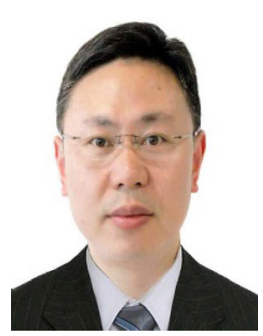

Haidou WANG. He received his Ph.D. degree in material processing engineering from Tsinghua University in 2003. He joined the Army Academy of Armored Forces from then on. He is a professor and

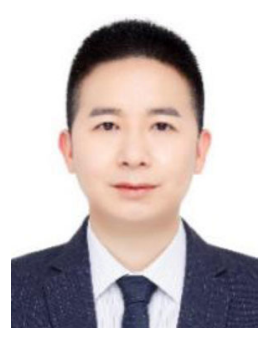

Guozheng MA. He got his Ph.D. degree in 2014 at the National Key Laboratory for Remanufacturing at Academy of Armored Forces, China. He is currently an associate researcher and a master tutor. He has authored or co-authored more than

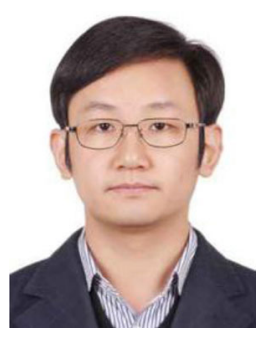

Haipeng HUANG. He got his M.S. degree in 2009 at China University of Geosciences (Beijing). $\mathrm{He}$ is a researcher at SINOPEC Lubricant

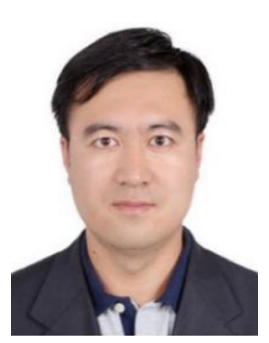

Guang'an ZHANG. He received his Ph.D. degree from Lanzhou University in 2008. After then, he works in the State Key Laboratory

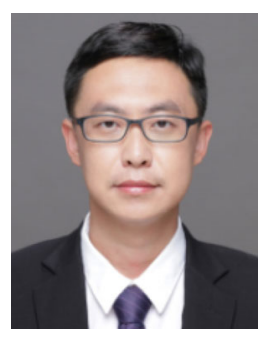

Wen YUE. He got his Ph.D. degree in 2009 at China University of Geosciences (Beijing). $\mathrm{He}$ is a professor at China University of the director of the National Engineering Research Center for Mechanical Product Remanufacturing. His current research areas cover the surface engineering, remanufacturing and tribology, especially in service life evaluation of surface coatings and solid film lubrication.

100 journal papers, and obtained more than 20 invention patents and 5 provincial or ministerial awards. He was supported by the Yong elite scientists sponsor ship program in 2016 by (China Association for Science and Technology) CAST and won "Wen shizhu's Maple Leaf Award" in 2020. His research interests are surface engineering, remanufacturing, and tribology.

Co., Ltd. He has authored or co-authored more than 20 journal papers. His research interests are lubricating additives, lubricants, and its application.

of Solid Lubrication, Lanzhou Institute of Chemical Physics, Chinese Academy of Sciences. His research interest focuses on the tribological mechanism and application of carbon-based thin films.

Geosciences (Beijing). He has authored or co-authored more than 150 journal papers. His research interests are lubricating additives and carbon-based thin films. 